\title{
Nuevos procesos de segregación urbana: la reestructuración de la exhibición cinematográfica en la Ciudad de México ${ }^{1}$
}

\author{
Ana Rosas Mantecón²
}

\section{C}

ON EL FIN DE APOYAR la exhibición de cintas nacionales y de calidad, así como de facilitar el acceso al cine a grupos de menores recursos, el gobierno del Distrito Federal ha anunciado su decisión de destinar 90 millones de pesos para la adquisición de cinco grandes salas —otrora palacios de la exhibición y ahora abandonadas en su mayoría-, ubicadas en el norte, centro y sur de la ciudad. Si bien parece una cifra insignificante frente al poco más de medio millar de espacios de exhibición con el que actualmente cuenta la Zona Metropolitana de la Ciudad de México (ZMCM), ${ }^{3}$ la propuesta llama la atención contra los signos con los cuales se ha desarrollado en el último lustro la exhibición cinematográfica: la concentración de la distribución y la exhibición en un puñado de empresas multinacionales (las "majors" controlan el 95 por ciento del mercado), el predominio de la oferta de películas norteamericanas, la proliferación de conjuntos de minisalas y la búsqueda de recuperación de espectadores provenientes fundamentalmente de los sectores medios y altos. ${ }^{4}$

1. Este artículo forma parte de la investigación "Auge, ocaso y renacimiento de la exhibición cinematográfica en la Ciudad de México, 1930-2000", la cual fue apoyada por el FoncA en el periodo 1998-1999.

2. Profesora-investigadora, Departamento de Antropología, UAM-Iztapalapa.

3. La zмсм hace referencia "a la extensión territorial que incluye a la ciudad central y a las unidades político-administrativas contiguas a ésta, así como a otras unidades con características urbanas" (Graizbord y Salazar: 120-125). En la actualidad comprende 43 unidades político-administrativas de dos entidades (el Distrito Federal y el Estado de México). En el mismo sentido puede interpretarse la iniciativa del Instituto de Cultura de la Ciudad de México, con el Programa "Cinito lindo... y querido" que proyecta películas de estreno - mexicanas y lationamericanas-, las cuales tienen un menor espacio dentro de las carteleras comerciales, en el Zócalo capitalino y en algunas plazas delegacionales. No sólo se brinda una oportunidad a miles de personas que no tienen acceso al cine, sino que se da un impulso al reencuentro de los públicos capitalinos con las películas mexicanas.

4. En el mismo sentido puede interpretarse la iniciativa del Instituto de Cultura de la Ciudad de México, con el Programa "Cinito lindo... y querido" que proyecta películas de estreno - mexicanas y 
El actual repunte de la exhibición cinematográfica en el país se ha desarrollado como parte de un proceso de acelerada transnacionalización, esto es, una cada vez mayor articulación subordinada al mercado mundial. México participa activamente como "potencia intermedia" en el flujo mundial de mercancías audiovisuales, que se sigue caracterizando por el dominio general de unos pocos países industrializados, en especial Estados Unidos. México exporta algunas películas, pero principalmente programas televisivos al resto de América Latina, así como a los mercados hispanoparlantes de Estados Unidos y del resto del mundo; también importa una muy alta proporción de su dieta televisiva, cinematográfica y de video (Sánchez Ruíz, 1998:104105). De hecho, 85.8 por ciento de las importaciones audiovisuales de América Latina procede de Estados Unidos (García Canclini, 1999).

Las salas se expanden por toda la Zona Metropolitana y aumentan las cifras de asistencia. Con poco más de un siglo de vida, los cinéfilos renacen de sus cenizas una vez más. Ni la televisión ni el video cumplieron con los augurios del fin del "siglo Lumiere". Cuando, a mediados de siglo, entró la televisión en los hogares, dando lugar al inicio de la recomposición de los circuitos audiovisuales, se había presentado una de las crisis más significativas de la exhibición cinematográfica a nivel mundial. Con una o dos décadas de retraso, la catástrofe se dejó sentir en la Ciudad de México, cuyo territorio se expandía permanentemente y no incrementaba en igual medida los equipamientos culturales: a la par que aumentaba el equipamiento televisivo, fueron descendiendo los espectadores, tal como lo podemos apreciar en la Gráfica 1.

GRÁFICA 1

Promedio de asistencia anual

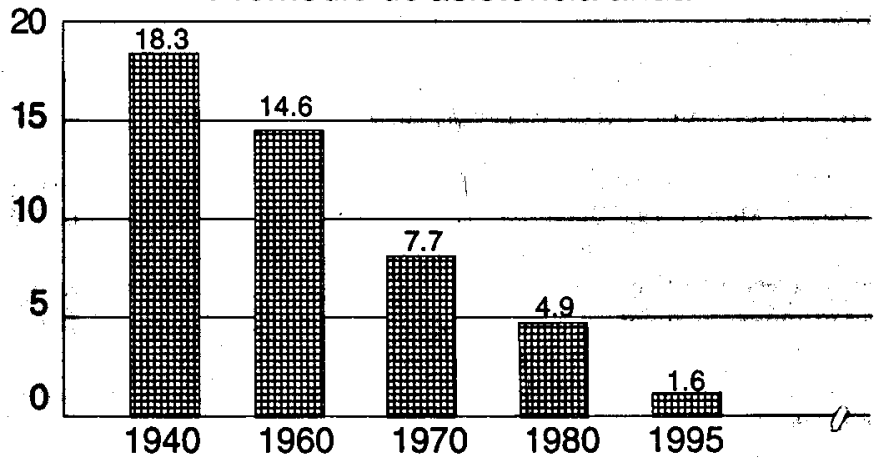

Fuente: INEGI/CANACINE

lationamericanas - , que tienen un menor acçeso a las carteleras comerciales, en el Zócalo capitalino y en algunas plazas delegacionales. No sólo se brinda una oportunidad a miles de personas que no tienen acceso al cine, sino que se da un impulso al reencuentro de los públicos capitalinos con las películas mexicanas. 
El cierre de salas no se hizo esperar: así como las primeras décadas del siglo atestiguaron la transformación de los teatros en cines, en los años recientes nos tocó presenciar la de éstos en estacionamientos, centros comerciales, auditorios, bares, taquerías, templos, salones para fiestas infantiles, bodegas o locales para renta de videos en los últimos tiempos. La falta de mantenimiento y deficiencias en la proyección habían terminado por volver un sofisma aquél lema de que "el cine se ve mejor en el cine". Los augurios no se dejaron esperar: con el siglo acabaría la época del cine como espectáculo masivo, la de las grandes salas oscuras como espacios de encuentro colectivo.

Las salas de cine no murieron, sino que resurgieron con nuevos brios sobre todo desde mediados de la década de los noventa. De hecho, el auge en la construcción de conjuntos de salas de exhibición en la Zona Metropolitana de la Ciudad de México (zMCM) en los últimos seis años pareciera constituirse en la excepción al proceso de desuso de los espacios públicos y un atenuante del subequipamiento general de las periferias metropolitanas. Como podemos apreciar en el Cuadro 1, tan sólo de 1995 a 1999, el número de salas casi se triplicó (de 211 ascendieron a 591), ${ }^{5}$ y los espectado-

CUADRO 1

Espectadores en la República Mexicana y en la zona metropolitana de la Ciudad de México 1990-1999

\begin{tabular}{||l|l|l|}
\hline AÑo & REP. MEXICANA & ZMCM \\
\hline 1990 & 197 millones & 54 millones \\
\hline 1991 & 170 millones & 44 millones \\
\hline 1992 & 134 millones & 37 millones \\
\hline 1993 & 103 millones & 31 millones \\
\hline 1994 & 82 millones & 30 millones \\
\hline 1995 & 62 millones & 28 millones \\
\hline 1996 & 80.4 millones & 34 millones \\
\hline 1997 & 95 millones & 41 millones \\
\hline 1998 & 104 millones & 46 millones \\
\hline 1999 & 130 millones & 46.8 millones \\
\hline
\end{tabular}

Fuente: CANACINE

5. El que el número de salas casi se triplique no debe verse en términos absolutos, ya que si bien no contamos con información sobre el total de butacas de las nuevas minisalas, podemos calcular que el 
res pasaron de 28 millones a 46,830,000, según los datos de la Cámara Nacional de la Industria Cinematográfica y del Videograma (CANACINE). Este proceso se dió también a nivel nacional, ya que en el mismo período los espectadores pasaron de 62 a 130 millones (cifra aún inferior a la de 1990), según registra la CANACINE.

CUADRO 2

¿Acostumbra asistir al cine?

\begin{tabular}{|l|c|c|c|c|c|c|}
\hline & 1994 & 1995 & 1996 & 1997 & 1998 & 1999 \\
\hline Sí & $50 \%$ & $42 \%$ & $38 \%$ & $35 \%$ & $39 \%$ & $39 \%$ \\
\hline No & $50 \%$ & $58 \%$ & $62 \%$ & $65 \%$ & $61 \%$ & $61 \%$ \\
\hline
\end{tabular}

Fuente: "Encuesta anual sobre el uso de los medios de comunicación en la Ciudad de México", periódico Reforma.

CUADRO 3

¿Dónde prefiere ver películas?

\begin{tabular}{|l|l|l|l|}
\hline & 1996 & 1997 & 1998 \\
\hline Cine & $59 \%$ & $63 \%$ & $53 \%$ \\
\hline Video & $30 \%$ & $27 \%$ & $24 \%$ \\
\hline Televisión & $9 \%$ & $9 \%$ & $17 \%$ \\
\hline No contestó & $2 \%$ & $1 \%$ & $6 \%$ \\
\hline
\end{tabular}

Fuente: "Encuesta anual sobre el uso de los medios de comunicación en la Ciudad de México" del periódico Reforma.

aforo de las décadas del cuarenta al sesenta no se ha recuperado. Por una parte en esos años llegaron a construirse salas hasta para 6000 asistentes y las actuales oscilan entre 150 y 800 asientos. Por la otra, continúan cerrando las grandes salas. 
Ante este panorama que parece no dejar espacio más que para el optimismo, ¿cómo explicar los registros que ha venido realizando el períodico Reforma con su "Encuesta anual sobre el uso de los medios de comunicación en la Ciudad de México" desde 1994, según los cuales la costumbre de asistir al cine ha venido decreciendo entre la población no sólo de la ciudad capital sino también de diversas ciudades de provincia?

La revisión del proceso de expansión de la exhibición cinematográfica en la ZMCM permite formular la hipótesis de que la recuperación de públicos es restringida, y está también orientada por los patrones de segregación que han ido conformando la ciudad. De hecho, son principalmente las clases medias y altas las que están volviendo al cine y es su mayor frecuencia de asistencia la que eleva las estadísticas. El resto de la población, mayoritaria, ve disminuir crecientemente esta práctica. La reconversión tecnológica y subdivisión de viejas salas hecha por la Organización Ramírez (Cinépolis) y la construcción de nuevos conjuntos a cargo de Cinemark, cadena de capital estadounidense, y Cinemex, con inversión australiana, estadounidense y mexicana, principalmente, ha generado en muchas ciudades grandes y medianas nuevos vínculos sólo con ciertos sectores de la población mexicana con el cine. El impulso primero a esta reconversión vino de la cancelación gubernamental del control de precios de entrada, con las modificaciones legislativas de 1992, que sentó las condiciones para la construcción de los sistemas de "multiplex" desde 1994.

Ya en ciudades europeas y norteamericanas se había recurrido a las salas múltiples para enfrentar la disminución de espectadores, en las que a distintos horarios se proyectan películas diferentes, en locales estratégicamente ubicados. El concepto de multiplex, traído de Estados Unidos, parece dominar el panorama de la exhibición en la actualidad. Las nuevas salas fundan su oferta, por una parte, en el mecanismo de diversificar — dentro de una gama muy limitada de opciones - las alternativas temáticas para el cinéfilo, proyectadas en horarios diversos. Por otra parte, recurren a la mejoría técnica de las instalaciones: mayor calidad de la imagen, del sonido, de los servicios anexos, y se ubican preponderantemente en zonas donde la capacidad adquisitiva de los habitantes circundantes va de lo medio a lo alto, de difícil acceso para los que carecen de automóvil o viven lejos de ellas, o tal vez inaccesibles por razones no sólo económicas sino también simbólicas.

Un reportaje publicado en la revista Expansión despeja cualquier duda: "A principios de los noventa, el panorama de la exhibición en México se asemejaba cada vez más a uno de esos áridos y polvorientos desiertos tan propios de los más genuinos westerns. Con la nueva filosofía imperante en la exhibición cinematográfica, el desfile de espectadores es incesante y el ritmo de trabajo brutal, signo inequívoco 
de que las salas de cine se han vuelto a convertir en un jugoso negocio en el actual panorama económico nacional" (Fernández, 1996:32-33).

Mientras continúan cerrando sus puertas las grandes salas -excepto cuatro o cinco, gracias a la exitosa exhibición de cine pornográfico- y sobreviven con dificultad buena parte de las subdivididas, la localización del conjunto de la oferta de espacios de exhibición puede percibirse aún como centralizada geográficamente, si bien este factor está en permanente transformación. El equipamiento sigue concentrado principalmente en la ciudad central, en el noroeste y, recientemente, en el suroeste de la ZMCM. De hecho, como ha señalado Ochoa Tinoco (1998:56), si trazamos una línea imaginaria de norte a sur, podemos apreciar que el poniente tiene cines y el oriente casi no. En el caso de los municipios conurbados, los cines se concentran en Ecatepec, Naucalpan y Tlalnepantla, aunque en su conjunto no suman ni el 15 por ciento del equipamiento, cuando habita ahí más de la mitad de la población. Como parte de este fenómeno de centralización de la oferta cinematográfica, se encuentra la concentración en la zona sur del mayor número de salas con una programación de calidad para cinéfilos (como la Cineteca Nacional, el Centro Cultural Universitario y otros cineclubes de Ciudad Universitaria).

La expansión de la oferta está orientada hacia la búsqueda de su público objetivo $^{6}$. Además, la actividad de exhibición se ha diversificado territorialmente tomando como eje el desarrollo de los centros comerciales, ámbitos privados de consumo colectivo que están dirigidos sólo a ciertos sectores de la población. Con atractivos

CUADRO 4

¿A qué dedica su tiempo libre los fines de semana y dias de descanso?

\begin{tabular}{|l|c|c|c|c|c|}
\hline Actividad & 1994 & 1995 & 1996 & 1997 & 1998 \\
\hline Ir al cine & $9 \%$ & $3 \%$ & $2 \%$ & $4 \%$ & $5 \%$ \\
\hline $\begin{array}{l}\text { Ir a un centro } \\
\text { comercial }\end{array}$ & $5 \%$ & $2 \%$ & $4 \%$ & $1 \%$ & $14 \%$ \\
\hline
\end{tabular}

Fuente: "Encuesta anual sobre el uso de los medios de comunicación en la Ciudad de México" del periódico Reforma

6. Hasta ahora las nuevas exhibidoras han buscado mayoritariamente al "público de clase media-alta y alta, el único capaz de pagar hoy el costo de ingreso a sus modernas instalaciones" (Fernández, 1996:48). En ciertas zonas de la ciudad, como la central, algunas han buscado atraer espectadores bajando los precios de entrada, pero con escasos resultados. En los recorridos de campo que realizamos en los cines ubicados en zonas populares, pudimos constatar la baja afluencia incluso en fines de 
diseños, seguridad e higiene, colaboran para que estos espacios trasciendan sus fines comerciales, y sirvan para citarse y sociabilizar. Una de las claves culturales de su éxito es cómo convergen en ellos diferenciación simbólica y libertad de comportamientos (Ramírez Kuri, 1998). La depuración de los públicos de cine aparece también en términos generacionales: mientras a mediados de siglo acudían las familias en su conjunto, parece darse ahora una predominancia de auditorios jóvenes, que son los que se acercan cada vez con mayor asiduidad a los centros comerciales. En el Cuadro 4 podemos observar el lugar que están tomando estos espacios de consumo en la reorganización del tiempo libre en la ZMCM.

Al elevado precio de los boletos de acceso a los cines, se suma el de los dulces, refrescos, palomitas, el estacionamiento, etcétera, que llega a representar a las empresas alrededor del 40 por ciento de su facturación (Fernández, 1996:42). En términos del salario mínimo diario, el precio de entrada llegó a representar 55 por ciento del mismo en 1945; luego en los años cincuenta bajó a un 30 por ciento. En los años sesenta se redujo hasta más o menos 15 por ciento y de 1970 a 1985 el precio de entrada osciló en la franja de 10 a 16 por ciento del salario mínimo diario del DF el que, a su vez, en ese período ha perdido mucho de su capacidad de compra (casi 50 por ciento entre 1976 y 1985) (Elizondo, 1991:19-20). En la actualidad, el salario mínimo diario es similar al precio de un boleto de acceso.

Mientras tanto, los sectores populares encuentran en los cines de barrio, en franca desaparición, y en algunos todavía ubicados en zonas comerciales populares (subdivididos), una opción de entretenimiento, limitada también por la oferta (cine porno, o proyecciones ya de segunda o tercera corrida, muy comerciales), la tecnología anticuada y malos servicios.

\section{El cine y los sectores sociales}

Desde su llegada a la Ciudad de México, el cinematógrafo cautivó a toda la población. Sin embargo, el papel de las salas como espacios de encuentro y de distinción social no parece haber sido homogéneo en el tiempo. Mientras en algunos salas era evidente que "el cinematógrafo juntaba a ricos y pobres, no jerarquizaba" y que "el pan de cada día fue la mescolanza durante el Porfirismo en cines e igle-

semana. El único día que la afluencia es adecuada es aquel en el cual los precios de entrada se reducen a la mitad, lo equivalente aproximadamente a una tercera o incluso cuarta parte del precio del boleto de un cine multiplex. 
sias". Muy pronto fue evidente la resistencia de las clases altas a mezclarse con la plebe, por lo que, en un contexto en el que se veían imposibilitadas crecientemente para mantener la exclusividad de su vida cultural, exigían funciones "de gala", en donde no hubiera "mezcolanza". 7 Las diferencias fueron estableciéndose paulatinamente de acuerdo a la ubicación de la sala, los precios de las diversas localidades y más tarde, cuando se construyeron los cines monumentales, al interior de los mismos (ver De los Reyes, 1993:67, 71, 91 y 170). En la Ciudad de México coexistieron los salones destinados a la alta sociedad con las carpas (ambulantes) y con los mejor establecidos salones populares, que alentaron la permanencia del cinematógrafo como espectáculo urbano.

En las primeras décadas del siglo, las salas de cine enriquecieron de maneras muy diversas la experiencia social de los capitalinos: además de constituírse en sede de reuniones políticas y de casillas electorales, así como de convivencias vecinales, alentaban el encuentro colectivo, que iba más allá del espectáculo, asemejándose al de las iglesias, por lo que se les conocía como "catedral cinematográfica", "templos del silencio", "templos del arte mudo" (De los Reyes, 1993:45).

Estudiosos del tema en México como Aurelio de los Reyes, Angel Miquel, Carlos Bonfil y Carlos Monsiváis han sugerido que cuando llegó el cine a la ciudad, ciertos grupos se resistieron a un proceso que había arrancado desde mediados del siglo xIX y que la llegada del cine vino a consolidar. Me refiero a la legitimación de los espectáculos populares $\mathrm{y}$, en particular, al fenómeno al que responde: la masificación de la cultura. Ante el crecimiento de un nuevo e importante grupo de consumidores, alimentado por los procesos de urbanización e industrialización, los empresarios ensayaron nuevas formas para dirigirse a los sectores populares. Para estos sectores se redujeron los precios de entrada a diversos eventos culturales, abriéndoles la posibilidad de cruzar el umbral de un espacio cuyo acceso les había estado vedado. Si a esto aunamos los cambios en la producción cinematográfica, que añadieron al cine documental el de ficción, con temáticas diversificadas, podremos entender el incremento del público atraído (Miquel, 1992:9).

Hacia los años veinte, la costumbre de asistir a una sala de proyección cinematográfica se había implantado ya entre el público, considerando el aumento en el número de espacios de exhibición y en la capacidad de los recién construídos, que se sumaron a los que continuaban funcionando. ${ }^{8}$ No obstante los altibajos, de $1930 \mathrm{a}$

7. En opinión de Miquel, sus gustos en materia de entretenimiento se orientaban más hacia la ostentación de sus haberes en la ópera y el teatro, las sesiones palaciegas de poesía y música romántica, las carreras de caballos y los toros, el art nouveau y las tiples, asi como la práctica del ciclismo (Miquel, 1992:8; ver también De los Reyes, 1993:25).

8. Así, mientras en 1910 la relación de habitantes por butaca era de 119 , una década más tarde disminuye a 16.4. Cotsa: IV. 
1955 la asistencia nacional al cine muestra las mayores tasas de crecimiento anual: el número de salas aumenta a una tasa de 6.6 por ciento, las localidades vendidas y el ingreso en taquillas a 8 por ciento, respectivamente.

Si bien los espacios de proyección no lograron seguir el galopante ritmo de la expansión urbana, no existía en estos años un problema de accesibilidad geográfica, ya que se encontraban dentro de una ciudad fácilmente transitable (en transporte colectivo o a pie). Las salas cinematográficas se convirtieron en símbolos urbanos particulares, y el emplazamiento en barrios tradicionales permitió un enriquecimiento de la sociabilidad también en zonas populares como Tepito, Bondojito, Tacuba, Guerrero, Peralvillo, etcétera.

El cine llegaba a todos los sectores, tal como rezaba el lema de la sala Florida, en el barrio de Tepito: "El cine para todas las clases sociales". Entre los años treinta y cincuenta se dió la relación de butacas por habitante más alta en la historia de la exhibición cinematográfica en la ciudad. Así, mientras en 1910 había 119 habitantes por butaca, en 1930 bajaron a 17.2 y en los cuarenta y cincuenta a 13.4 (Cotsa, 1978:IV).

El auge de la asistencia a los cines fue impulsado también por el uso diversificado del espacio urbano y las estructuras barriales que enmarcaban el creciente consumo de películas en sus salas de exhibición. En estos años, acudir al cine formaba parte de un abanico de prácticas en las que se desenvolvía la vida pública de la urbe: con la masificación de las diversiones populares, las ofertas culturales eran diversas; las crónicas de mediados de siglo nos relatan el desarrollo de una intensa vida pública en calles, plazas, cafés, restaurantes, carpas, circos, cantinas, cabarets, teatros, cines y salones de baile.

A partir de la segunda mitad del siglo, la exhibición de cine en México fue perdiendo su carácter pluriclasista y se fue enfocando crecientemente hacia los sectores populares, tanto por la temática de las películas nacionales, su decreciente nivel de calidad como por las condiciones de exhibición predominantes. En lo que respecta a la exhibición de películas nacionales, fueron las clases altas las primeras en emigrar. Las clases medias, de mayor importancia numérica, aparecen en el centro de las discusiones sobre el auge y derrumbe de la industria cinematográfica nacional. Para Emilio García Riera, por ejemplo, el problema del cine mexicano radicó en haber perdido a la clase media: mientras ésta crecía menos películas se hacian para ella. Según este autor, hubo un acuerdo tácito en las altas esferas oficiales y privadas para que el cine mexicano fuera abaratado frente a la competencia extranjera, resignándose a perder al público de clase media y alta, apreciación en la que coincide el director de cine Alejandro Galindo (1968). El único cine mexicano que conti- 
nuó siendo apreciado por estos sectores fue el conocido como “de la época de oro", que continuó proyectándose pero a través de la televisión. Así, nuestro cine nacional se resignó a buscar un público continental analfabeto o semianalfabeto, de menores exigencias, con la excepción del sexenio del presidente Luis Echeverría (19701976) que intentó volver a atraer al público urbano medio hacia el nuevo cine que se producía al abrigo estatal (Cotsa:142).

Las clases bajas parecen haber sido las eternas espectadoras del cine nacional, sobre todo en los ámbitos provincianos. La difícil situación para el cine mexicano se acentúa a partir de los años setenta, cuando el público natural se restringió aún más al fronterizo y al hispanohablante de Estados Unidos: en 1981 dicho auditorio aseguraba el $75 \%$ de los ingresos del cine nacional de producción privada (García Riera, 1985:324-325). "Corrimos al público de los cines -reconoce el empresario Carlos Amador - por la mala calidad de las películas; la gente ya no iba a ver películas de desnudos y majaderías; ahora hay que hacer que el público regrese " (Rivera, 1992:50).

Respecto a la exhibición en general, desde los años sesenta todos los sectores fueron bajando sus frecuencias de asistencia (ver Gráfica 1). Incluso a partir de los setenta el público humilde empezó también a desertar de las salas de cine y a ver cada vez más televisión (García Riera, 1985:195). Estudios del Banco Nacional Cinematográfico muestran que si bien todos los grupos sociales han disminuído su asistencia a las salas por las crisis sucesivas de la exhibición, ya desde 1970 hay diferencias en las frecuencias de asistencia por sector: los estratos altos tiene una mayor asistencia que los medios y éstos a su vez superan a los populares, que se convierten crecientemente en los mayores consumidores televisivos (Banacine, 1970 y 1976).

El proceso en Estados Unidos fue distinto. No obstante que el cine se mantuvo durante mucho tiempo como un espectáculo esencialmente popular (había salas ubicadas en suburbios obreros, a donde llegaba una fuerte población de emigrantes, aunque igualmente había cines en los barrios habitados por la clase media), y la primera estrategia para enfrentar la crisis de los años treinta, cuando cerraron cerca de un tercio de las salas, fue la baja de los precios de entrada, a partir del final de la guerra la exhibición se reorientó hacia las clases medias. Entre 1948 y 1950 los precios aumentan en un 37 por ciento. Un alza tan elevada provocó una disminución de la asistencia entre las clases populares. Por otra parte, las salidas familiares al cine, que eran una costumbre del período de entreguerras, se hicieron más raras, al pesar más la evolución de los precios sobre las familias. La baja de público de las salas de cine norteamericano entre 1948 y 1950 fue del 33 por ciento, o sea, del mismo orden que el alza de precios de las entradas. Todo esto se desarrolló en una 
época en que el parque de televisores era todavía modesto, lo cual hace concluir a Patrice Flichy que no fue la llegada de la televisión la que hizo caer la audiencia cinematográfica (con una baja del 50 por ciento en cinco años); una parte del público, y en especial el popular y familiar, ya había abandonado las salas (Flichy, 1993:210-211).

\section{La recomposición de las prácticas audiovisuales}

Si bien no fue la entrada de la televisión en los hogares la causa principal del descenso de la asistencia a los cines, sí le dio un impulso definitivo. En 1946 había en Estados Unidos 6 estaciones emisoras de televisión y 30 mil aparatos receptores; nueve años más tarde se multiplicaron las emisoras a 511 y los aparatos a 46,700,000. En el mismo lapso el número de salas de cine disminuyó de 21 mil a 14 mil (Barbachano,1974:33). De manera semejante se produjo el fenómeno en diversos países europeos: aumentos del equipamiento televisivo a la par de la acentuada disminución de la asistencia a las salas. En Europa, el número de salas descendió de 42 mil a 27 mil entre 1958 y 1978 (Ramón Zallo, 1988:108).

Diversos factores se conjugaron para conformar lo que ha sido reconocido como el inicio de la recomposición de los circuitos audiovisuales. Hablo de recomposición del mercado audiovisual para no dejar la idea de una simple competencia entre medios. Como comprobamos en los estudios efectuados en 1992 y 1993 (García Canclini, 1994), el modelo de desarrollo cinematográfico organizado para difundir las películas en las salas se agotó al instalarse la televisión en casi la totalidad de los hogares y, a partir de 1985, con la expansión del video. De hecho, la televisión integró como parte de su programación a las películas realizadas hasta ese momento, por lo que se convirtió en otro espacio de exhibición filmica que dió durante varias décadas un gran impulso a la cinematografía nacional. En la actualidad las películas ocupan el primer lugar como género televisivo, según el estudio de Sánchez Ruíz. Por otra parte, en la reorganización de los circuitos audiovisuales, la exhibición en salas apenas aporta alrededor del 25 por ciento de las ganancias, muy por debajo de lo que ofrecen el video, la televisión abierta y la restringida (ver García Canclini, 1994:33-34).

Si bien encontramos al final del siglo xx que los públicos no optan tajantemente por uno u otro medio sino que pueden ser considerados multimedia, en la recomposición de los mercados audiovisuales, el cine como experiencia de sociabilidad pública resulta más accesible para sectores medios y altos; para los populares, la televi- 
sión y el video son las posibilidades a las que más se recurre para el entretenimiento. Así lo confirman las investigaciones sobre consumo cultural en la periferia de la Ciudad de México, realizadas por Nieto y Nivón, en donde la práctica de acudir al cine entre los sectores populares es muy limitada.

El renacimiento de la exhibición cinematográfica se ha insertado en la actualidad dentro de los procesos de reestructuración de los escenarios de consumo y tiempo libre: su creciente vinculación a la expansión de los centros comerciales en algunas de las principales ciudades latinoamericanas se da articulada a nuevos procesos de segregación y a la centralidad que han adquirido los medios electrónicos-especialmente la televisión y la radio- en el consumo cultural de las poblaciones urbanas de la región (ver Sunkel, 1999).

\section{Comentarios finales}

La masificación era a la vez.la integración de las clases populares a la sociedad y la aceptación por parte de ésta del derecho de las masas a bienes y servicios que hasta entonces sólo habían sido privilegio de unos pocos. Si bien desde mediados del siglo $\mathrm{xIX}$, el desarrollo de la comunicación de masas abrió la posibilidad de que amplios sectores de la sociedad accedieran a ella, a finales de siglo nuevos procesos de segregación y diferenciación social limitan dicho desarrollo, propician la desarticulación de los espacios de encuentro colectivo y ponen en crisis una forma de sociabilidad ligada a las relaciones en el espacio público. Si bien es cierto que los propios medios han abierto otras posibilidades de encuentro, no relacionadas con la copresencia, es innegable que asistimos a una crisis de lo que tradicionalmente se ha entendido por vida colectiva, sobre todo en las grandes ciudades.

Por su propia lógica, no existen visos de que al cambio de siglo se modifiquen estos nuevos procesos de segregación y diferenciación social. Es necesario, más que nunca, dar un impulso a políticas públicas y civiles que incidan en el fenómeno, como las que mencionamos al comenzar, que buscan promover la exhibición con un sentido muy diferente al prevaleciente.

¿Qué está en juego? Como lo ha señalado Mabel Piccini, asistimos a nuevas formas de desarraigo y a la lenta desarticulación de una parte de los espacios tradicionales de encuentro colectivo, espacios que no sólo se ligaban a rituales públicos y gregarios, sino que constituían la base de orientación y pertenencia de las diferentes comunidades en el territorio. Así como a principios de siglo el cine logró consolidar- 
se como fenómeno de masas, ahora sobrevive a fuerza de elitizarse: los sistemas de multicines se expanden selectivamente por la ciudad. De este modo, en lo que toca al cine, llegamos al fin de siglo y entramos al siguiente con una nueva segregación de la diversión pública.

\section{Bibliografía}

Alfaro, F. y Ochoa, Alejandro, Espacios distantes aún vivos. Las salas cinematográficas de la ciudad de México, UAM-Xochimilco, México, 1997.

Arredondo, Pablo, "La industria cinematográfica", en Comunicación social, poder y democracia en México, Guadalajara, Universidad de Guadalajara, 1986, pp. 69-93.

Banacine, Estudio de la exhibición cinematográfica en el área metropolitana del valle de México, ICATEC, Consultores, Estudio realizado para Operadora de Teatros, México, 1971.

Barbachano, Carlos, El Cine, arte e industria, Barcelona, Salvat Editores, 1974.

Canacine, La industria cinematográfica mexicana. Perfil económico, Cámara, Nacional de Cinematografia, México, 1989.

Canacine, Exposición y análisis de la problematica actual en la industria cinematográfica, Cámara Nacional de la Industria Cinematográfica, México, 1994. Cotsa, "Desarrollo de las salas cinematográficas en la Ciudad de México (18961978)", en Las salas cinematográficas en la Ciudad de México y su área metropolitana, Compañía Operadora de Teatros, México, 1978.

De la Vega, Eduardo (comp.) Bye bye Lumiere... Investigaciones sobre cine en México, Guadalajara, Universidad de Guadalajara, colección: textos de comunicación y sociedad, Serie: Cuadernos.

De los Reyes, Aurelio, Cómo nacieron los cines, Instituto de Investigaciones Estéticas, n. 50-2, México, 1982, pp. 285-296.

Eibenschutz, Roberto (coord.), Bases para la planeación del desarrollo urbano en la Ciudad de México, uAM-Xochimilco/Miguel Ángel Porrúa Ed., México, 1994, 2 vols.

Elizondo, Jorge, “La exhibición cinematográfica. Retrospectiva y futuro”, en Pantalla, México, 1991, n. 15, publicación de la Dirección General de Actividades Cinematográficas de la Coordinación de Difusión Cultural/unam.

Fernández, Joaquín, "Exhibición cinematográfica, lo que el viento regresó", en Expansión, 9 de octubre de 1996, México, pp. 32-48. 
Flichy, Patrice, Una historia de la comunicación moderna. Espacio público y vida privada, Gustavo Gili, México, 1993.

García, Néstor (coord.), Cine, televisión y video: hábitos de consumo audiovisual en México, (Distrito Federal, Guadalajara, Mérida, Tijuana), junio de 1992.

— La globalización imaginada, Paidós, México, 1999.

García Riera, Emilio, El cine y su público, FCE, México, 1974, Colección Testimonios del Fondo 11.

- Historia del cine mexicano, SEP, Foro 2000, México, 1985.

Graizbord, Boris y Héctor Salazar, "Expansión física de la Ciudad de México", en Atlas de la Ciudad de México, Departamento del Distrito Federal y El Colegio de México, México, 1987, pp. 120-125.

Inegi, Estadísticas de cultura y recreación. Serie Boletín de estadísticas continuas demográficas y sociales, año 1, n. 1, julio, Instituto Nacional de Estadística Geografia e Informática, México, 1994, pp. 1-9.

Inegi, Estadisticas de cultura, Cuaderno 1 y 2, Instituto Nacional de Estadística, Geografia e Informática, México, 1980-94.

Miquel, Angel, “Cines y públicos en el México de principios de siglo", en Dicine, n. 44, marzo, México, 1992, pp. 8-11.

Nieto, Raúl, "Experiencias y prácticas sociales en la periferia de la ciudad" en Néstor García Canclini, (coord.), Cultura y comunicación en la ciudad de México, Grijalbo, vol. 1, México, 1998, pp. 234- 276.

Nivon, Eduardo, "De periferias y suburbios. Territorio y relaciones culturales en los márgenes de la ciudad" en Néstor García Canclini, (coord.), Cultura y comunicación en la ciudad de México, Grijalbo, v. 1, México, 1999, pp. 204-233.

Ochoa, Cuauhtémoc, Las salas cinematográficas en la Ciudad de México en tiempos de cambio 19982-1997, tesis de mestría en Planeación y Políticas Metropolitanas, UAM-Azcapotzalco, México, 1998.

Piccini, Mabel, "Acerca de la comunicación en las grandes ciudades", en Perfiles Latinoamericanos, FLACSO, año 5, n. 9, México, 1996, pp. 25-46.

Ramírez Kuri, Patricia, "Coyoacán y los escenarios de la modernidad" en Néstor García Canclini, (coord.), Cultura y comunicación en la ciudad de México, Grijalbo, v. 1, México, 2000, pp. 320-367.

Red Mexicana de Acción Frente al Libre Comercio, "La guerra de las pantallas", en Alternativas, septiembre-octubre, n. 22, México, 1998, pp. 11-14.

Rivera, Héctor, "Los exhibidores privados se disponen a enfrentar el embate de los multicinemas norteamericanos", en Proceso, n. 814, junio de 1992, México, pp. 48-53. 
Sánchez, Enrique, "El cine mexicano y la globalización: contracción, concentración e intercambio desigual", en Horizontes del segundo siglo. Investigación y pedagogía del cine mexicano, latinoamericano y chicano, Univesidad de Guadalajara/Instituto Mexicano de Cinematografia, México, 1998, pp. 101-133. Sunkel, Guillermo (coord.), El consumo cultural en América Latina, Convenio Andrés Bello, Santafé de Bogotá, 1999.

Zallo, Ramón, Economía de la comunicación y la cultura, Ediciones Akal, Madrid, 1988. 